\title{
The origins of violence
}

\author{
H J Eysenck Department of Psychology, Institute of Psychiatry, London
}

\section{Editor's note}

This is one of a group of papers read at the London Medical Group conference on 'Violence' which was held at the Royal College of Surgeons of England, Lincoln's Inn Fields, London in February 1979. Professor Eysenck outlines the various hypotheses put forward to explain the origins of violence in our present day society and examines in more detail the contribution the psychologist has to make in explaining the problems associated with violence. He concludes that both biological and social factors are responsible and that the development of 'conscience' in humans, when children, through conditioning is necessary to help control violent responses.

\section{Introduction}

It is a platitude to state that man is a bio-social organism, and that his conduct is determined both by biological and by social factors. Phylogenetically the central nervous system, the cortical structures organising it, and the autonomic system are the product of hundreds of millions of years of evolution, culminating in some four million years' development of recognisably hominid forms. It is absurd to imagine that this long-continued development would not have left traces governing many aspects of our behaviour.

Again, man is a social animal, and the development of language has made it possible for social roles and modes of conduct to be handed down from one generation to another in written and verbal form. This is a relatively novel and very powerful mode of social evolution which takes its place beside biological evolution, and cannot be overlooked in deciding upon the major determinants of human conduct, including antisocial and violent behaviour.

In spite of its obviousness, this simple fact of duality of determination is denied by extremists on both sides. Biological factors are denied by many sociologists, anthropologists, behaviourists like Watson and Skinner, who advocate the doctrine of the 'empty organism' - i.e. a black box kind of being which receives stimuli and produces responses, without any apparent intervening nervous system. Sociologists try to explain antisocial behaviour in terms of social factors such as inequality of income, poverty, poor housing, etc., disregarding the fact that for over the last 30 years there has been a considerable improvement in all these matters, while violence has increased rather than decreased! Anthropologists like Margaret Mead give descriptions of tribes like the murderous Mundugumor and the peaceful Arapesh, suggesting that extremes of conduct like these are entirely the product of social factors. All these groups hark back to the doctrine of Rousseau and John Locke; they seem to postulate, as Locke did, a tabula rasa as typical of the mind of man, a tablet on which society can write anything it wishes.

On the other side we have people like E O Wilson, the father of sociobiology, Dawkin with his 'selfish gene', Ardrey, Morris, and the vaguely eponymous Messrs Tiger and Fox, who take their clue from ethology and zoology, and try to account for human behaviour exclusively in terms of biological factors we share in common with animals.

To say that clearly human behaviour is nog exclusively governed by our genes, nor by our sociat upbringing, is not saying very much, but it is the beginning of wisdom to discount such simplistic extrapolations from the extremists who fail to discern the onesidedness of their position.

This is not to say that such simplistic and onesided statements are not often quite appealing. W M S Russell, for instance, attributes violence and associated types of antisocial behaviour to overcrowding, citing many animal studies in which there appears a statistical relationship between these two variables, and extends this to human society. Interesting as this hypothesis of his may be, it must be clear that this is merely an analogy, and that there is no direct evidence from the human field to support this view. It might seem intuitively obvious that in our society there is more violence in groups of people suffering most from overcrowding, but a simple look at the methodological difficulties attending such a comparison will make it doubtful whether any scientifically meaningful conclusions can be drawn from the known facts. The fact (if it is a fact!) that overcrowding and violence are found associated in certain groups cannot necessarily be interpreted to mean that overcrowding causes violence. Such a conclusion would only be possible if we had assigned people at random to an overcrowded and a normal control situation, and it had been found that those in the overcrowded situation developed violent conduct to a greater extent than those in the normal control situation. 
Unfortunately (or fortunately) such random assignment of individuals is impossible on practical and ethical grounds, and what we have is a much more difficult situation in which people differing considerably in intelligence, personality, predisposition for mental illness, etc. sink into the poorer and more deprived sorts of conditions, or rise out of them into more salubrious positions, thus confounding personality qualities and status. It is known, for instance, that the psychotic and psychopathic individuals tend to sink in the social scale, this frequently ending up in poor and overcrowded conditions; it is also known that such people are more given to violence. Thus the possibility cannot be ruled out that it is precisely those personal qualities which lead to violence and antisocial behaviour, which condemn a person to live in overcrowded conditions. There are no easy solutions to complex problems of this kind, and the public appeal of simple, single-cause explanations should not lead us to forego scepticism and critical scientific evaluation of such proposals.

\section{The contribution of psychology}

What is the contribution that psychology can make to the solution of the problem of violence? The first point to note is that there are two problems here. The first relates to individual differences. Under similar conditions, some people will act in an antisocial and violent manner, others will not; what is it in the personality make-up of a given individual that leads to one type of behaviour or the other? The second problem relates to changes in antisocial and violent behaviour in a society over time; why is it that there has been a considerable increase in violence over the past 30 years in most Western (and also Communist) countries? These two problems may or may not have the same explanation, but it is important to keep them separate as clearly the possibility exists that quite different explanations may be called for in order to account for the fact.

Psychologists start out with the fact that, as Professor McLean has pointed out, man has a triune brain, i.e. a brain morphologically divided into three main parts, arising at different times, and serving different functions. First, there is a reptile brain, i.e. the brain stem and the hind brain; next we have the paleo-cortex; last the neo-cortex, whose tremendous growth over the past four million years has distinguished human beings from all other types of animals. The neo-cortex is the organ of rational learning, mediated by language; much more ancient, and responsible for emotional behaviour and reactions, is the paleo-cortex, and in particular the limbic system, which coordinates and governs the activities of the autonomic nervous system. The limbic system too has a language, but it is non-verbal and uses the mechanisms of Pavlovian conditioning. Just as Pavlov conditioned dogs to respond with salivation to the sound of the bell, pairing the bell with the sight of food, so conditioning associates $\varrho$ previous neutral stimuli with emotional reactions. As I have pointed out in my book on Crime and Personality, man has to learn to behave in a socially? acceptable manner, and to acquire a 'conscience'; $\overrightarrow{\bar{F}}$ this is done by means of a process of conditioning, $\overline{0}$ in which antisocial acts constitute the conditioned등 stimuli (corresponding to the bell in Pavlov's experiment), and the punishment meted out by parents, teachers, peers, and people in authority constitutes the unconditioned stimulus (correspond- - s ing to the food in Pavlov's experiment). Thus on $\overrightarrow{0}$ hundreds or even thousands of occasions a child $\overrightarrow{\vec{H}}$ misbehaves and is punished; slowly he learns to $\omega$ anticipate punishment for antisocial activities, and $\overline{3}$ the anxiety and fear produced as a result of this $\Phi$ conditioning effectively prevents him on future occasions from acting in such an antisocial manner, $\overrightarrow{-}$ even though he may be unobserved, and no punish-or ment may be forthcoming. There is ample experi-응 mentation with animals and children to demonstratethis process, and to show that we can indeed acquires? a 'conscience' in this manner.

Individual differences in antisocial behaviour under similar conditions arise because there are marked individual differences in conditionability, i.e. in the way with which conditioned responses are 6 formed, the strength of these conditioned response and the difficulty of extinguishing them. It has beenc shown that cortical arousal is highly correlated wh the speed of forming conditioned responses, their strength, and their resistance to extinction; thiso cortical arousal is correlated with certain personality types, particularly introversion, and if indeed conditioning is at the basis of socialised conduct, 3 then we would expect introverts to behave in a socially responsible manner, extraverts to be rather more asocial or antisocial in their conduct, a prediction that has been amply borne out in many studies, not only in the Western world, but also in:Third-world countries like India, and in countries 3 behind the Iron Curtain like Hungary. Thus personality differences account for a substantial/ part of the variability we find in human reactionso to similar situations, as far as antisocial and violent behaviour is concerned.

\section{Personality and genetics}

It is important to note that these personality differences are largely genetically determined, and it $\sigma$ would therefore come as no surprise to find that antisocial behaviour too is to a marked extent genetically determined. Studies of monozygotice and dizygotic twins, for instance, indicate that the former are much more concordant for criminalo behaviour than are the latter; if one twin is a criminal, the other is four times as likely to bed a criminal if he is an identical twin than if he is a 
fraternal twin of the proband. Similarly, studies of adopted children have shown that with respect to antisocial and violent conduct these resemble their true parents much more closely than their adoptive parents, although the latter provide practically their entire social environment. There is thus very little doubt about genetic determinants of this type of conduct, mediated through personality differences and differences in arousal and conditioning.

\section{Explaining the amount of violence}

How can we explain the changes in the amount of violence observed during the past 30 years or so ? Clearly genetic factors cannot have changed to any extent in such a short period of time. However, the conditioning theory provides us with a suggestive and possible answer. Successful conditioning is in part a function of the innate properties of the organisms, making it easy or difficult for the organisms to be conditioned; it is also in part a function of the number of conditioning trials. Pavlov already noted that all dogs can be conditioned, but some are easily conditioned, taking only two or three pairings of the conditioned and the unconditioned stimuli, whereas others may take two or three hundred. Thus, given that genetically the population today is no different from that of 30 years ago, the differences in the prevalence of antisocial and violent behaviour may be due rather to a lowering in the number of conditioning trials to which children are exposed during their period of growing up. The general climate of permissiveness has led many parents, teachers and other people in authority to reject the very essential role they play in transmitting and enforcing the rules of society, and children nowadays grow up with a much reduced chance of acquiring a proper 'conscience' due to the lack of conditioning experiences to which they are exposed by their elders and betters. Sometimes the Government takes a hand, as in passing the 1969 Children and Young Person's Act, effectively making it impossible for the courts to take a part in this conditioning process; children and young persons are nowadays permitted to indulge in almost any kind of violent and criminal activity without any serious fear of punishment. Thus differences in prevalence of violent and criminal conduct may be $\frac{c}{d}$ due very largely to a failure on the part of society to $\propto$ provide the conditioning experiences which are $\underset{F}{5}$ required for the child to grow up into a law-abiding citizen.

\section{Conclusion}

This, in brief, is the kind of message the psychologist $\overline{\bar{N}}$ would have to contribute to a discussion of the $\mathbb{\nabla}$ origins of violence. Inevitably the account here given is much too brief and dogmatic, but a more detailed treatment of the topic is available in my $\vec{\circ}$ book on Crime and Personality, where also references $\overrightarrow{\vec{\omega}}$ are given to the very large experimental literature on $\stackrel{\omega}{\rho}$ this topic. It will be seen that the major causes of violence in human society are partly biological, $\overparen{D}$ partly social. There are innate propensities towards $i$ violence, antisocial and criminal behaviour which are $\overrightarrow{\vec{t}}$ associated with low cortical arousal and extraverted $O$ personality; these can be partially controlled by $\frac{9}{3}$ social influences, exerted through a process of $\rightarrow$ Pavlovian conditioning. Society may choose to $\mathbb{D}$ exert a strong influence through these mechanisms, $\frac{\mathbb{D}}{\mathbb{D}}$ allowing parents, teachers, magistrates and other $\frac{\mathbb{D}}{3}$ persons in authority to provide the necessary $\underset{\mathbb{D}}{2}$ conditioning experiences which the child needs to develop a proper 'conscience', or society may prefer $\vec{\theta}$ a state of general permissiveness, in which parents teachers, magistrates and other persons in authorit are discouraged from exerting their influence in thf direction. We are now reaping the consequences of $\bar{\partial}$ preferring the second of these alternatives to the former; no doubt in due course the pendulum will $\varnothing$ swing back to a more sensible and reasonable halfway position between permissiveness and extreme $\stackrel{ }{\exists}$ severity.

Gradually, then, science is feeling its way towards the more precise interpretation of social and biological factors and their interaction in producing antisocial, criminal and violent behaviour. It is $\frac{\square}{\sigma}$ already quite obvious that no view leaving out one 3 set of factors or the other is tenable any longer; $\delta$ what is needed is a more precise statement of the $₹$ role played by biological and social factors, and 0 experimental studies to verify or disprove hypotheses based on these views. 